\title{
ASSESSING PATHOLOGIES ON VILLAMAYOR STONE (SALAMANCA, SPAIN) BY TERRESTRIAL LASER SCANNER INTENSITY DATA
}

\author{
J. García-Talegón ${ }^{\text {a, }}$, S. Calabrés ${ }^{b}$, J. Fernández-Lozano a , A.C. Iñigo c; H. Herrero-Fernández , \\ B. Arias-Pérez ${ }^{\mathrm{b}}$, D. González-Aguilera ${ }^{\mathrm{b}}$ \\ a Department of Geology; Faculty of Sciences, University of Salamanca, Salamanca, Spain - (talegon@usal.es, jfl@usal.es) \\ ${ }^{\mathrm{b}}$ Department of Cartographic and Land Engineering; High School of Ávila, University of Salamanca, Ávila, Spain - \\ (sergio.calabres@gmail.com,daguilera@usal.es, benja@usal.es) \\ c Spanish National Research Council, Instituto de Recursos Naturales y Agrobiología de Salamanca, Salamanca (CSIC) \\ (adolfo.inigo@irnasa.csic.es, quinto_cicerón@yahoo.es) \\ * Corresponding author
}

Commission V, WG V/4

KEY WORDS: Pathologies, Cultural Heritage, Villamayor Stone, Terrestrial laser scanner, Photogrammetry, Single-lens reflex camera, Remote sensing, Supervised classification.

\begin{abstract}
:
This paper deals with the assessing of pathologies in façades using a variety of intensity data provided by different terrestrial laser scanner. In particular, a complex building built in the Villamayor Stone that is to be candidate as a Global Heritage Stone Resource has been chosen as study case. The Villamayor Stone were quarrying for the construction and ornamentation of monuments in Salamanca, declared World Heritage City by UNESCO in 1988. The objective of this paper is to assess the pathologies of Villamayor Stone and compare the results obtained through the laser techniques with the classical techniques of mapped pathologies (i.e. visual inspection). For that intensity data coming from laser scanners will be used as non-destructive techniques applied to the façades and several retired plaques (after of building restoration) of Villamayor Stone with pathologies (fissures, scales, loss of matter, humidity/biological colonization) carried to the laboratory. Subsequently it will perform different comparisons between the accuracy reached with the different sensors and a high precision model setup on laboratory which performs as "ground truth". In particular, the following objectives will be pursued: i) accuracy assessment of the results obtained in in situ and laboratory; ii) an automation or semi-automation of the detection of pathologies in Villamayor Stone; iii) discriminate the different types of Villamayor Stone used in the façades in function of the radiometric response; iv) establish a methodology for detection and assessing of pathologies based on laser scanner intensity data applied to monuments and modern buildings built in Villamayor Stone.
\end{abstract}

\section{INTRODUCTION}

The conservation of cultural heritage is one of the fundamental concerns and potential of modern society and particularly, historic infrastructures largely characterize modern Europe. Historical constructions present a cultural legacy that needs to be preserved. This generic term includes a wide range of constructions such as residential buildings, religious buildings, or even civil structures such as bridges. Many of these constructions are still in service, which is a proof of their historic and engineering value, so their preservation must be a vital concern of modern and advanced reflective societies. However, when these constructions need to be evaluated from the point of view of engineering, many restrictions make it difficult to obtain accurate and realistic analyses. Among others, the main aspects that characterize the engineering evaluation of historical constructions are:

- Complex and often unique geometry.

- The uncertainty and diversity of the mechanical properties of the materials, and construction technologies.

- Unknown techniques and processes during the staged construction.

- Vulnerability and monumental status of the construction.

Close-range remote sensing has evolved importantly in the last decades in terrestrial environments: new technologies such as laser scanning have significantly contributed to this growth. In particular, terrestrial laser scanners have gained popularity in the last decade related to the tasks involving geometric characterization. The terrestrial laser scanner provides a great volume of information quickly and with high accuracy. The information is formed, at least, by a point cloud with spatial coordinates of the points and metric capabilities. In addition, the main advantage of this technology is their non-destructive nature (Genovese, 2005), together with the crosscutting applications of the technologies to many different fields: archaeology (Lamberts et al., 2007), civil engineering (Lubowiecka, et al., 2009; González-Aguilera et al., 2008), geology (Buckley et al., 2008) and geomorphological analysis (Armesto et al., 2009), among others. Thus, this technology represents a very attractive and powerful tool for the study of historical constructions, but they still need to be explored further. In fact, radiometric information, provided by the intensity measurements in the case of laser technology, is used less frequently, so that its potential for classification tasks and recognition of different materials should be investigated. Recently radiometric information has started to use in the detection of different pathologies in granites (González-Jorge et al., 2012) and detection of humidity and lichens in granite (Rodriguez-Gonzálvez et al., 2013). Although, nowadays several works have been performed in granites and other materials, never an exhaustive study has been realized over the Villamayor Stone. 
The objective of this paper is to assess the pathologies of Villamayor Stone and compare the results obtained with the intensity data coming from laser scanners with the classical techniques of mapped pathologies (i.e. visual inspection). For that it will be used several kind of laser scanners applied to the façades of a complex building "El Tormes" located in Salamanca (Spain) and to several retired plaques (after of building restoration) of Villamayor Stone with pathologies.

The paper has been structured as follows: after this introduction, Section 2 presents the Villamayor Stone as a Global Heritage Stone and its pathologies. Section 3 outlines in details the methods developed; and the final two sections summarize the experimental results and present conclusions drawn from the study.

\section{MATERIALS}

\subsection{Villamayor Stone: Heritage Stone}

In Salamanca (Spain), which was declared a World Heritage City by UNESCO in 1988, the construction of the principal religious and civil monuments maintains a fixed pattern in the use and position of the Villamayor Stone that is used. In the lower parts of monuments and columns (base, shaft and capital) other types of Heritage Stones have been used such as silicified conglomerates, Sandstone Salamanca Formation (Tosca Stone); monzogranite, Granite of Los Santos; and Leucogranite with tourmaline of Martinamor (Stone of Vaugnerite) (GarcíaTalegón et al., 2014; López-Plaza et al., 2007a, b).

Villamayor Stone is an arkosic stone of the Middle Eocene age and belongs to the Cabrerizos Sandstone Formation that comprises braided fluvial systems and paleosoils at the top of each stratigraphic sequence. The sandstone is known by several names: i) It is known locally and in historical documents as Franca Stone; ii) Villamayor Stone because the quarries are located in Villamayor de Armuña; iii) the Golden Stone due to its patina that produces a ochreous/golden colour on the façades of monuments of Salamanca which are built with this natural stone. Villamayor Stone (Golden Stone) is presented as a candidate to be designated Global Heritage Stone Resource (García-Talegón et al, 2014). Currently, Villamayor Stone is using for cladding of the façades of the new buildings. Villamayor stone (Golden Stone) has several varieties (GarcíaTalegón et al, 2014): i) Carbonated Variety: the fine-grained stone, microporous, is partially cemented by dolomite, $27 \%$ (bulk porosity), ii) Clay and fine Variety: ochre colour, microporous, with smectite with iron oxides, 30\% (bulk porosity), is very compact with abundant clay matrix, iii) Medium grained Variety: without cement, low clay matrix and with iron oxides present, 38\% (bulk porosity) and macroporous. Main components for all three varieties: Quartz (up to 60\%), feldspars, 2:1 layered silicates (smectites), palygorskite-type fibrous silicates, and small amounts of micaceous minerals (illite/mica).

Golden Stone (García-Talegón et al., 2014) has a particular physic characteristic like its absorption index (about 13.55\%). It does that this stone be highly porously and therefore very sensible of the humidity.

Furthermore, the façades of the monuments demonstrate a surprising uniformity in which it can be observed seen that the ashlars have different intrinsic characteristics given the wide variety of types of Villamayor stone.

\subsection{Villamayor Stone: Pathologies}

Looking at the Villamayor stone monuments it can be deduced that on the façades exposed to the sun and the joint action of wind and rain (Rives and Vicente, 1993), but without the constant humidity to produce their arenization, the patina is more intense. Two types of surface modification of the Villamayor Stone in these monumental microenvironments have been defined: i) on vertical surfaces which have good drainage and are exposed to the sun, good conservation of the stone can be observed and it acquires a beautiful golden patina and ii) if the stone is located in zones of frequent humidity, water with or without salts (nitrates, chlorides , sulfates, phosphates, etc.) which is located in the lower parts of the monument rises from their bases by capillary action. The patina is a symptom of the condition of the stone, and contributes to its conservation (Vicente and Brufau, 1986).

During the years 2007/2008, detailed mapping pathologies and different varieties of Villamayor Stone are preceded, due to the detachment of small portions of the façade cladding close to the copings of the cornices and the terraces of the building (Figure 1). The decay of the Villamayor Stone was consequence of the bad drainage system in the copings of the building, together join to the humidity sensibility of this stone and abrupt changes of temperature (frost weathering "ice wedge effect" by increasing water volume when its physical state changes) were producing a deterioration in the copings in a short time (less than 7 years). The mean decay of the Villamayor Stone is leading to microfissures, scales, flakes and loss of matter (Figure 1) following ICOMOS glossary (2011).

From the climatic data of Salamanca city, it is concluded that the climate of Salamanca can be defined as a Mediterranean with a continental trend, with an annual mean temperature of $12.2^{\circ} \mathrm{C}$. The range of daily temperature fluctuations may be as large as $35{ }^{\circ} \mathrm{C}$. The absolute maximum temperature measured over the last 30 years is $39.4^{\circ} \mathrm{C}$, while the absolute minimum is $-12.6{ }^{\circ} \mathrm{C}$. Yearly average precipitation is about $372.5 \mathrm{~mm}$, mainly in spring and autumn, July and August being characterized by strong droughts.

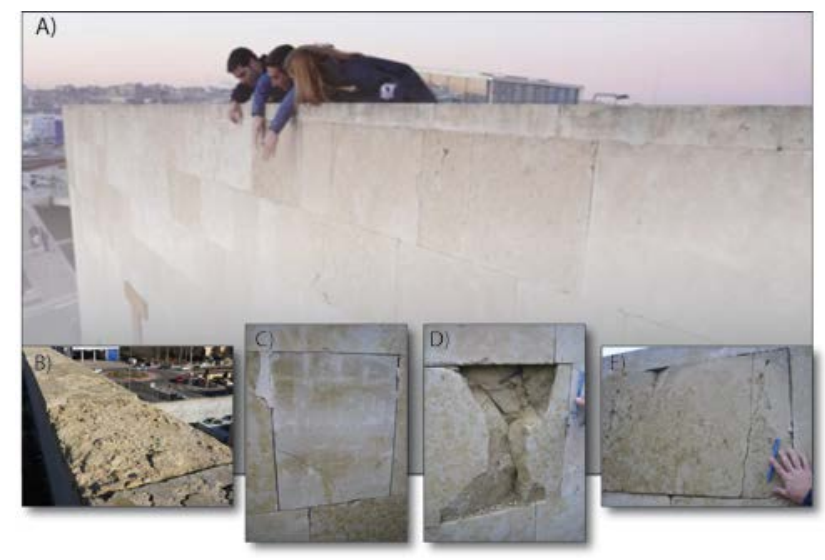

Figure 1.Villamayor Stone decay. A.- Southwest cladding façade with significant decay of the Villamayor Stone. B.Material loss and scaling in the copings of the cornices. C.- Fissures in the grained Villamayor Stone. D.- Fissures and material loss in the clay-fine Villamayor Stone and its anchoring. E.- Fissures and cracking in the clay-fine Villamayor Stone below the coping of the cornice. 


\section{METHODS}

\subsection{Equipments}

For the documentation of the façades and specific plaques on the laboratory two different terrestrial laser scanners were used with different characteristics and data acquisition principles:

The FARO Focus 3D laser scanner is based on the principle of continuous wave, with a wavelength of $905 \mathrm{~nm}$. This device measures distances in a range of $0.60-120 \mathrm{~m}$ with a point measurement rate of 976,000 points per second. It has an accuracy of $0.015^{\circ}$ in normal lighting and reflectivity conditions and a beam divergence of $0.19 \mathrm{mrad}$, equivalent to $19 \mathrm{~mm}$ per $100 \mathrm{~m}$ range. The field of view covers $320^{\circ}$ vertically and $360^{\circ}$ horizontally with a $0.009^{\circ}$ of angular resolution and the returning intensity is recorded in 11 bits.

The Trimble GX is a laser scanner bases in the principle of time of fly, with a wavelength of $534 \mathrm{~nm}$. The range measure is between 2-350m with a point measurement rate of 5000 points per second. It has an accuracy of $2,5 \mathrm{~mm}$ per $100 \mathrm{~m}$. The field of view covers $60^{\circ}$ vertically and $360^{\circ}$ horizontally.

The main characteristics and technical specifications of the lasers equipments used in this study are resumed in Table 1.

\begin{tabular}{|l|l|l|}
\hline \multirow{4}{*}{$\begin{array}{l}\text { Principle of measure } \\
\text { Wavelength }\end{array}$} & $\begin{array}{l}\text { TRIMBLE GX } \\
\text { Deflection System }\end{array}$ & Faro Focus 3D \\
\cline { 2 - 3 } Fight & Continuous & Wave \\
Field of vision & $360^{\circ} \mathrm{Hm}$ x $60^{\circ} \mathrm{V}$ & $360^{\circ} \mathrm{H}$ x $305^{\circ} \mathrm{V}$ \\
Standard deviation & $1.4 \mathrm{~mm}$ in $\mathrm{D}<50 \mathrm{~m}$ & $2 \mathrm{~mm}$ in $\mathrm{D}=25 \mathrm{~m}$ \\
Measure rank & $2-350 \mathrm{~m}$ & $0.6-20 \mathrm{~m}$ \\
& & \\
Angular resolution & Horizontal: $12^{\prime \prime}$ & Horizontal: 33" \\
& Vertical: $14 "$ & Vertical: 33" \\
Laser divergence & $3 \mathrm{~mm}$ in $50 \mathrm{~m}$ & $0.16 \mathrm{mrad}$ \\
Scan Velocity & 5000 points/s & 122.000 points/s \\
\hline
\end{tabular}

Table 1: Specifications of the different terrestrial laser scanners used in this study, features referred to vendors documents.

\subsection{Data acquisition}

The study was divided in two parts. First part allowed getting information with terrestrial scanner laser after previously inspection of the zone with potential interest in pathological analysis. Second part was focused in the analysis and treatment of the obtained point cloud with different software.

The data acquisition had two phases that where carry out in 2007 and 2014. The first phase had the objective the 3D documentation of the complex building "El Tormes" located in Santa Marta de Tormes (Salamanca, Spain). The equipment used was Trimble GX. It was realized 5 stations with a base distance between $30-50 \mathrm{~m}$ covering three of the four façades and obtaining a point cloud with a resolution of $10 \mathrm{~mm}$ in the mains parts of the façades and $5 \mathrm{~mm}$ in the copings where the main pathologies were presented.
The second part of the study was realized in December of 2014 in the photogrammetric laboratory of the Polytechnic High School of Ávila (Spain). The terrestrial laser scanner used in this part, was the Faro Focus 3D. In this occasion many plaques retired of the façades in the 2007 restoration were scanned and analysed. A resolution of $1.5 \mathrm{~mm}$ with an object distance between 3-7 $\mathrm{m}$ was used.

In both campaigns the laser surveying was supported by a photographic documentation realized with a single-lens reflex (SLR) digital camera, Panasonic Lumix DMC-FZ38. The photographs had the objective to grant additional RGB information to the intensity values provided by laser scanners.

\subsection{Data processing}

The raw laser point clouds were filtered and segmented in order to remove those points that were not part of the Villamayor Stone. In the case of the complex building "El Tormes", the point cloud alignment was done by a solid rigid transformation using common surfaces and supported by the iterative closes point algorithm (Besl and McKay, 1992). In addition, the different images acquired with the SLR digital camera were registered through a camera resection process based on collinearity condition (Kraus, 1993). As a result, RGB information can be used as additional radiometric information in the assessment of pathologies. Finally, orthoimages with the different intensity values, including RGB information, were generated in order to establish a common cartographic product for analysing the Villamayor Stone.

Two types of orthoimages were created. The first type has a ground sample distance (GSD) of $10 \mathrm{~mm}$ and covers the complete façade surveyed in 2007. The second type has a GSD of $5 \mathrm{~mm}$ and only covers the copings and those plaques analysed on laboratory in 2014. Both types were created using the RGB and intensity values. Orthoimages were generated based on the anchor points method (Kraus, 1993). This method consists of applying an affine transformation to each one of the planes formed by the optimised triangular mesh, which was obtained from the point cloud determined by the laser. Through the collinearity condition (Albertz and Kreiling, 1989), the pixel coordinates of the vertices of the mesh are calculated, and the mathematical model of the affine transformation directly relates the pixel coordinates of the registered image and of the orthoimage.

On the other hand, an expert analysis of the pathologies was performed in situ. As a result, themathic cartography was obtained using the orthoimages and drawing manually the pathologies.

\subsection{Recognition of Villamayor Stone varieties and humidity/biological colonization: Non-supervised classification}

With the purpose to compare the results obtained in 2007 with pathological cartography realized in the classic way by the expert, a non-supervised classification using the intensity values of the orthoimages of the copings was carried out.

This classification has been realized with the Maximum Likelihood (ML) method using Isodata clustering algorithm to determine the characteristics of the natural groupings of cells in multidimensional attribute space and stores. The ML classifier quantitatively evaluates both the variance and covariance of the category spectral response patterns when classifying an 
unknown pixel. The resulting bell-shaped surfaces are called probability functions (Equation (1)), and there is one such function for each spectral category (Lillesand et al., 2004).

$$
\operatorname{Pr}(k / g)=-\ln \left|\sum k\right|-\left(g-\mu_{k}\right)^{T} \sum k^{-1}\left(g-\mu_{k}\right)
$$

where

$$
\begin{aligned}
& \sum k=\text { covariance matrix } \\
& \mu_{k}=\text { mean vector }
\end{aligned}
$$

\subsection{Villamayor Stone pathologies: fissures and scaling}

3.5.1 High resolution Digital Model: The analysis of fissures and scales was performed by mean of the digital model obtained after processing the laser point cloud. The mathematical approach used for the calculation of the surface grid was completed by applying the nearest neighbour interpolation method with a $0.2 \times 0.2 \mathrm{~mm}$ grid spacing. Subsequent analysis of the interpolated, surface was completed by applying a low-pass Gaussian filter based in the convolution matrix of the signal ( $\mathrm{Z}$ values) and following the Gaussian functions proposed by Nixon (2008).

Once the grid was obtained, a colour scale with normal shading was applied in order to quantify the volume lost. The volume reconstruction was finally calculated by subtracting the nonaltered rock surface from the study samples. The visual inspection of the grid and the orthoimages allowed the digitalization and mapping of pathologies (fissures and scaling) in the Villamayor Stone.

3.5.2 Fourier Analysis: The digital model was mathematically processes under a two-dimensional Fourier analysis in order to assess the contribution of fissures and scaling to the final surface geometry observed. Mathematically, the Fourier transform can be expressed in the space domain as follows (Bracewell and Bracewell, 1986) (Equation (2)):

$$
f(\omega)=\int_{-\infty}^{\infty} f(\mathrm{x}) e^{i \omega x} d x
$$

Since the space domain function $\mathrm{f}(\mathrm{x})$ has a single and unique wavenumber domain function, and viceversa, it can be assumed that, by a given wavenumber, the function can be transformed into the space domain by using the inverse Fourier
Transformation (Arfken and Weber, 1985). The reciprocal relation is represented by (Equation (3)):

$$
f(x)=\frac{1}{2 \pi} \int_{-\infty}^{\infty} f(\omega) e^{-i \omega x} d \omega
$$

where $\omega$ is an angular wavenumber in radians per millimetre (for a given $\mathrm{x}$ in millimetres). The wavenumber in cycles per millimetre is $\omega / 2 p$ ( $p$ accounts for period).

The inverse Fourier transform aimed to convert from the wavenumber domain back into the original space domain using the Oasis Montaj MAGMAP module and applying a raised cosine filter (Kekre, et al., 1982) (Equation (4)):

$$
\begin{gathered}
L(k)=\cos ^{n}\left[\frac{\pi}{2}\left(\frac{k-k_{0}}{k_{1}-k_{0}}\right)\right] \text { for } k_{0} \leq \mathrm{k} \leq k_{1} \\
\mathrm{~L}(k)=1 \text { for } k<k_{0} \\
\mathrm{~L}(k)=0 \text { for } k>k_{0}
\end{gathered}
$$

where $\quad K_{0}=$ initial wavenumber

$K_{1}=$ final wavenumber

$n=$ degree of function

\section{EXPERIMENTAL RESULTS}

\subsection{Results obtained from Trimble GX}

The cartographic results obtained during the campaign executed in 2007 are outlined in Figure 2. The field work was carried out around the different façades of the complex building "El Tormes", the most interesting façades from a pathological point of view were those with orientation north and south-west. A total of 5 stations were required to cover the façades at a distance between $30-50 \mathrm{~m}$. The resolution of the data capture was $10 \mathrm{~mm}$ for the façades and $5 \mathrm{~mm}$ in the copings where the main pathologies were presented. Moreover, the façades were photographed at the same distance with a SLR digital camera, Panasonic Lumix DMC-FZ38. The number of points per side is 3millions in the laterals and 7 millions in the main façades.

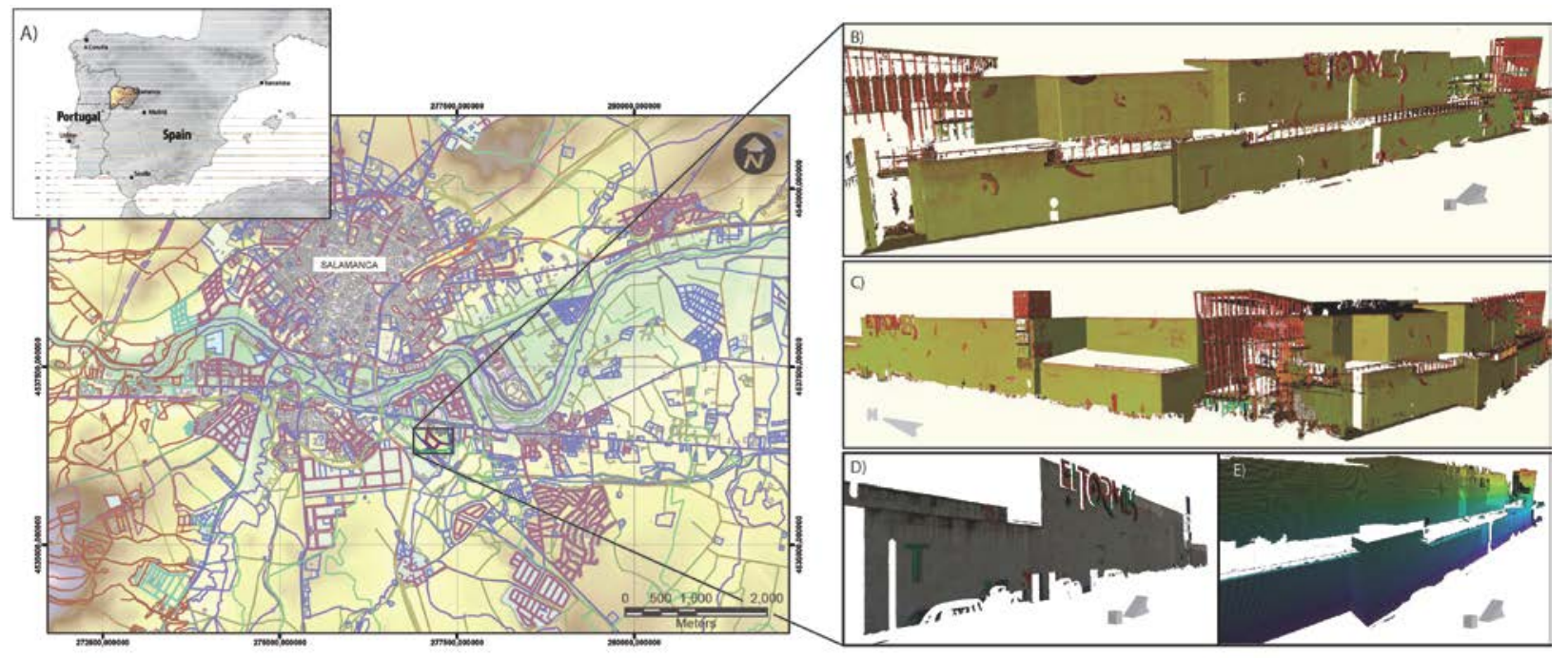

Figure 2. A,- Localization of the complex building studied (“El Tormes”, Salamanca, Spain). B and C.- Intensity 3D models acquired with the Trimble GX laser scanner. D.- True colour 3D model. E.- Height Map. 


\subsection{Results obtained from the non-supervised classification.}

The non-supervised classification executed over the orthoimages using the different intensity data has shown different grades of humidity affection. These differences respond to a combination of factors controlled by the microenvironments of the façades (orientation, the copings of the terraces, etc.) and the diversity of intrinsic properties of Villamayor Stone. For instance, façades facing north (Figure 3 A) are prone to maintain high rates of humidity aimed by an important decrease in daily sun insulation and hence low evaporation rates.

The Villamayor Stone porosity $(>30 \%)$ favors humid conditions, increasing the development of lichen growth (Figure 2 D). The non-supervised classification of rock pathologies shows the impact of humidity in the cladding, affecting the first four top-lines, and clearly marked by different degrees of intensity along the north façade (Figure 1 and Figure $3 \mathrm{~A}$ ); whereas the western façade only presents humidity affection in the coping and first top-line of the cladding (Figure $2 \mathrm{C}$ and Figure $3 \mathrm{~B}$ ). In addition, the classification allowed us to differentiate between two different varieties of Villamayor Stone represented by changes in rock reflectivity. These differences were based on composition, internal structure and degree of surface weathering (Figure $2 \mathrm{C}$ and $2 \mathrm{~B}$ ).

In the eastern part of the building there was no cladding façade and the southern one did not show any sights of humidity nor the presence of lichens.
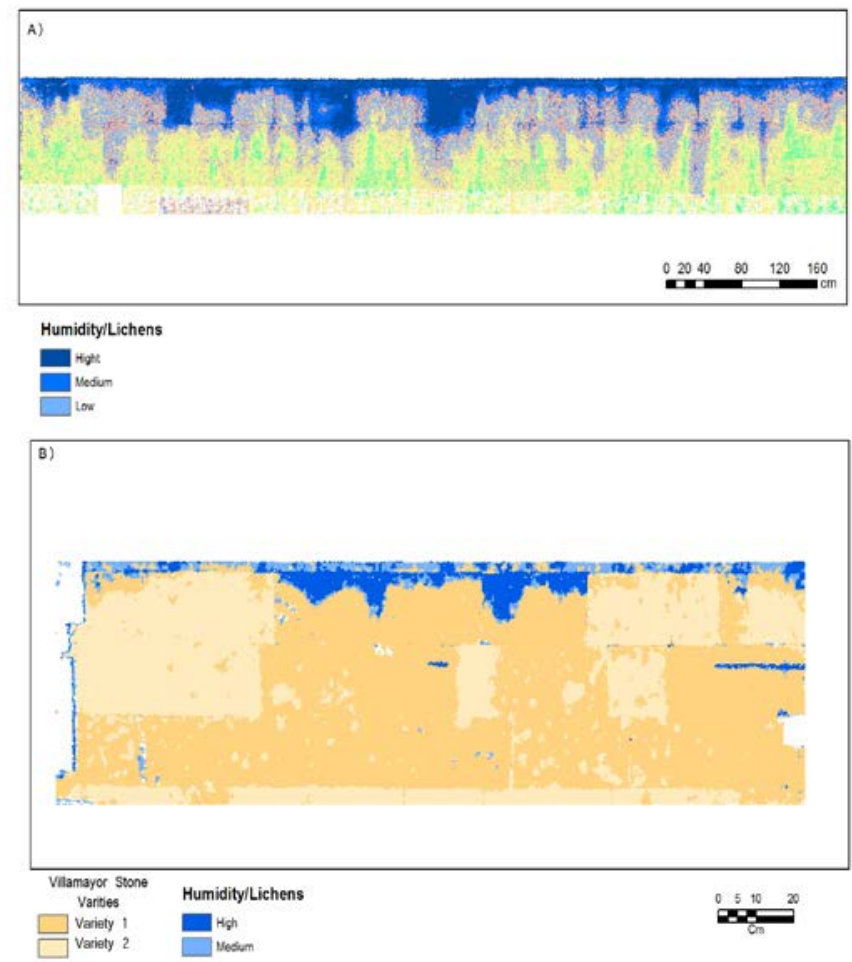

Figure 3. A and B.- Results of the non-supervised classification zoned North and Southwest of the studied building, respectively. Variety 1: clay-fine Villamayor Stone; Variety 2: carbonated Villamayor Stone

\subsection{Results obtained from the cracking and detachment analysis}

Digital Model obtained from TLS point cloud of an altered Villamayor Stone plaques removed from the façade of the studied building were analyzed by adding different hypsometric shading. The color patterns aimed to identify different areas of damage characterized by scaling and fissures (Figure 4). These pathologies were digitized in the obtained orthoimages (Figure $4 \mathrm{~B}$ ) and several profiles were performed (Figure 4 C). Fissures were clearly identified in the profiles, marked by a sharp pattern in elevation (Figure $4 \mathrm{C}$ profile 1-4). However, this method strongly depends on the visual interpretation and experience of the observer and the resolution of the method of data acquisition.

A)
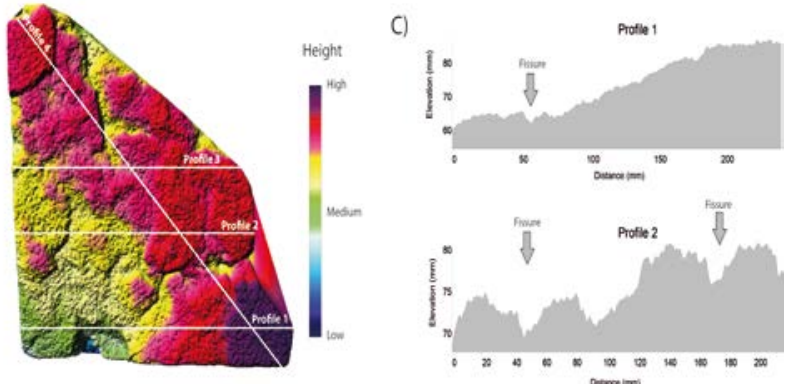

B)
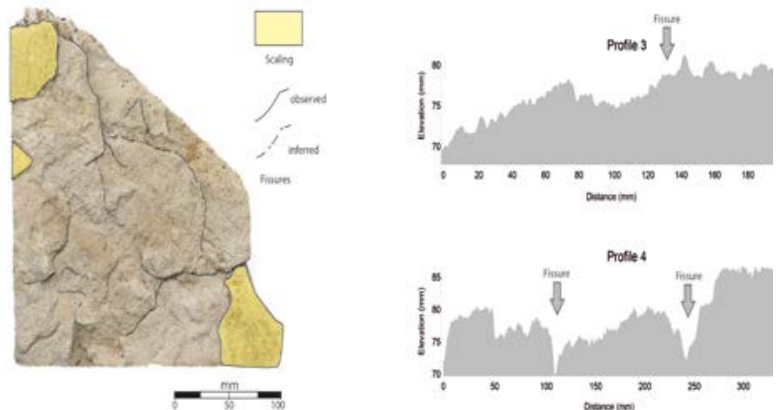

Figure 4. A. Hypsometric shading of the D M. B.- Orthoimage showing the fissures and scaling affecting the Villamayor Stone plaque. C.-Longitudinal and transversal profiles of the plaque marking the position of the fissures (arrows).

In addition to the analysis of the Digital Model (D M) and the visual interpretation of the different pathologies observed, it carried out an inverse 2D-Fourier Analysis over the obtained DM grid. The results aimed to identify two characteristic wavelengths at $25 \mathrm{~mm}$ and $50 \mathrm{~mm}$. The subsequent application of a low pass raise cosine filter at $25 \mathrm{~mm}$ shows the imprinted pattern related to fissuring, characterized by short-spaced highs and lows (Figure $5 \mathrm{~A}$ ). In addition, the $50 \mathrm{~mm}$ wavelength marked the position of scaling pathologies represented by the presence of clearly defines highs. The Fourier analysis offers a good quality control of this type of pathologies affecting the Villamayor Stone and could be use for the study and identification of patterns of fissuring and scaling in building façades. It is also a fast method for mapping of rock pathologies which needs to be combined with other methods of analysis such as orthoimages or true-color laser-derived images based on point clouds obtained from TLS. 

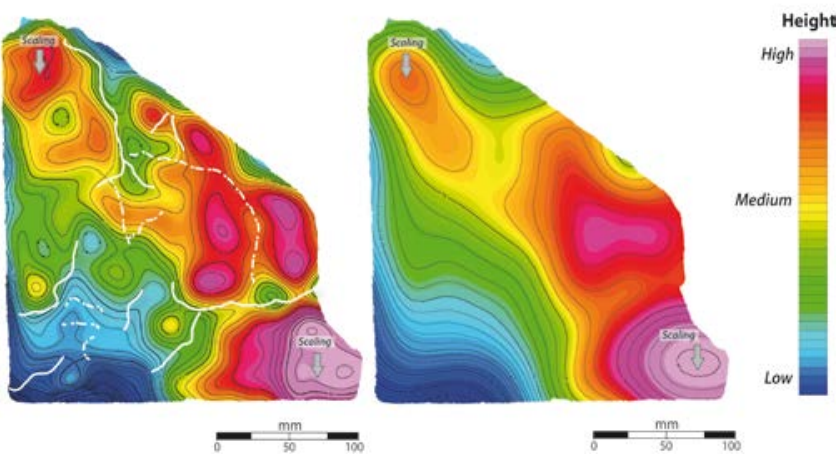

Figure 5. Results of the Fourier transformation. A.- Results from $25 \mathrm{~mm}$ grid. B.-Results from $50 \mathrm{~mm}$ grid.

\section{CONCLUSIONS}

The application of geomatic technology in the Villamayor Stone, recognized as a Global Heritage Resource, has successfully contributed to improve the analysis of rock pathologies. The integration of terrestrial laser scanner and photogrammetry was used for the first time in Villamayor Stone in order to complement visual observations and petrophysical characterization carried out by experienced rock-pathologists. The comparison of Faro and Trimble GX scanner technology has confirmed the capacity of the former to improve data resolution and lowering the data acquisition time. Nonsupervised classification of these data enhances to distinguish between different patterns of spectral intensity aiming to:

- Differentiate among pathologies such as humidity and biological colonization.

- Assess the total surface affected by rock pathologies.

- Measure the surface involved in rock scaling and fissuring.

Finally, the new approach based on the treatment of the point cloud allowed the generation of high resolution digital models, which were used for volume lost quantification in the past 10 years. In addition, the Fourier analysis has demonstrated the capability to provide a fast and accurate response in the interpretation of rock pathologies. This methodology could help, in addition to visual exploration, for the identification of fissures and scaling in façades.

\section{ACKNOWLEDGEMENTS}

The authors are grateful for funding from an agreement with the ING INMUEBLES S.A.U. to perform this work. We would like also to recognize Mrs. Cuca Gonzalo, C.C.Tormes's manager and her team, who gave us all of the information and facilities that we needed.

\section{REFERENCES}

Albertz, J., Kreiling, W., 1989 Photogrammetrisches Taschenbuch. Wichmann.

Arfken, G., Weber, H. J., 1985. Mathematical Methods for Physicists Academic.New York, 1985, 309.
Armesto J, Lubowiecka I, Ordóñez C, Rial F. FEM modeling of structures based on close range digital photogrammetry. Automation in Construction, 2009; 18: 5969.

Besl, P., McKay, N., 1992. A Method for Registration of 3-D Shapes. IEEE Transactions on pattern analysis and machine intelligence, 14(2), pp. 239-256.

Bracewell, R.N., Bracewell, R., 1986. The Fourier transform and its applications, McGraw-Hill New York.

Buckley, S.J., Howell, J.A., Enge, H.D., Kurz, T.H., 2008. Terrestrial laser scanning in geology: data acquisition, processing and accuracy considerations. Journal of the Geological Society, 165, pp. 625-638.

García-Talegón, J., Iñigo, A. C., Alonso-Gavilán, G., VicenteTavera, S., 2014. Villamayor Stone (Golden Stone) as a global heritage stone resource from Salamanca (NW of Spain). Journal of Geological Society of London (Special Publication), DOI:10.1144/SP407.19.

Genovese, R., 2005. Architectural, archaeological and environmental restoration planning methodology: historic researches and techniques of survey aiming to conservation, In: CIPA 2005 XX International Symposium, Torino, Italy.

Gonzalez-Aguilera, D., Gomez-Lahoz, J., Munoz-Nieto, A., Herrero-Pascual, J., 2008. Monitoring the health of an emblematic monument from terrestrial laser scanner. Nondestructive Testing and Evaluation 23 (4), pp. 301-315.

González-Jorge, H., Gonzalez-Aguilera, D., RodriguezGonzalvez, P., Arias, P., 2012. Monitoring biological crusts in civil engineering structures using intensity data from terrestrial laser scanners. Construction and Building Materials, 31, pp. 119-128.

ICOMOS, 2011. Illustrated Glossary on Stone Deterioration Patters. Paris: Monuments and Sites XV. ICOMOS.

Kekre, H.B., Sahasrabudhe, S.C., Goyal, N.C., 1982. Raised cosine function for image data interpolation, Computers \& Electrical Engineering, 9, 131-152.

Kraus, K., 1993. Photogrammetry .Fundamentals and Standard Processes Vol 1. 4th Edition. Dümmler. Bonn, Germany.

Lambers, K., Eisenbeiss, H., Sauerbier, M., Kupferschmidt, D., Gaisecker, T., Sotoodeh, S., et al., 2007. Combining photogrammetry and laser scanning for the recording and modelling of the Late Intermediate Period site of Pinchango Alto, Palpa, Peru. Journal of Archaeological Science, 34 (10), pp. 1702-1712.

Lillesand, T. M., Kiefer, R. W., Chipman, J. W., 2004. Remote sensing and image interpretation (No. Ed. 5). John Wiley \& Sons Ltd.

López-Plaza, M., González-Sánchez, M., Iñigo, A. C., 2007a. La utilización del leucogranito turmalinífero de Martinamor en los monumentos de Salamanca y Alba de Tormes. Studia Geologica Salmanticensia, 43, pp. 247-257. 
López-Plaza, M., González-Sánchez, M., García de los RíosCobo, J. I., Cortazar-Estibaliz, J., Iñigo, A. C., Vicente-Tavera, S., López-Moro, J. J., 2007b. La utilización de rocas vaugneríticas en los monumentos de Salamanca. Studia Geologica Salmanticensia, 43, pp. 115-125.

Lubowiecka, I., Armesto, J., Arias, P., Lorenzo, H., 2009. Historic bridge modelling using laser scanning, ground penetrating radar and finite element methods in the context of structural dynamics. Engineering Structures, 31 (11), pp. 26672676.

Nixon, M., 2008. Feature extraction \& image processing. Academic Press. 399pp

Rodríguez-Gonzálvez, P., Pascual, J.H., Aguilera, D.G., Nieto, Á.L.M., Mancera-Taboada, J., Martín, N.S., 2013. Aplicación de técnicas geomáticas al análisis y diagnóstico de patologías en el Patrimonio Arquitectónico. Mapping, 161, pp. 4-19.

Rives, V., Vicente, M. A., 1993. Formas de alteración de la arenisca de Villamayor en distintos microambientes de edificios salmantinos. In: Alteración de granitos y rocas afines, empleados como materiales de construcción, Madrid, Spain, pp. 75-82.

Vicente, M. A., Brufau, A., 1986. Weathering of the Villamayor arkosic sandstone used in buildings, under a continental semiarid climate. Applied Clay Science, 1(3), pp. 265-272. 